\title{
Chromium Deposition on Cobalt-Based Alloys by Pack-Cementation and Behaviour of the Coated Alloys in High Temperature Oxidation
}

\author{
Grégory Michel, Patrice Berthod*, Stéphane Mathieu, Michel Vilasi and Pierre Steinmetz
}

\author{
Institut Jean Lamour (UMR CNRS 7198), Department 2 - Chemistry and Physics of Solids and Surfaces, Nancy - \\ University, B.P. 70239, 54506 Vandoeuvre-lès-Nancy, France
}

\begin{abstract}
Two TaC-strengthened cobalt-based alloys, with compositions Co-10Cr-0.25C-4.4Ta and Co-10Cr-0.5C-8.7Ta (wt.\%) underwent Cr-deposition by pack-cementation, followed by heat-treatment to allow $\mathrm{Cr}$ diffusing deeper in their sub-surface. Thereafter they were tested for 50 hours at $1200^{\circ} \mathrm{C}$ in a thermobalance. These alloys were successfully enriched in chromium, with a maximal content on surface of about 30wt.\% and a depth of enrichment of several hundreds of micrometers. This allowed a chromia-forming behavior of the cemented alloys despite the $10 \mathrm{wt} . \% \mathrm{Cr}$ of the bulk. This was especially true for the $\{\mathrm{C}, \mathrm{Ta}\}$-richest alloy the oxidation kinetic of which was wholly parabolic and analogous to a $\mathrm{Ni}-30 \mathrm{Cr}$ alloy known for its good behavior in oxidation at $1200^{\circ} \mathrm{C}$. The parabolic constants and chromia-volatilization constants were at the same levels of the Ni-30Cr ones. However, the chromium enrichment step, especially the diffusion heat-treatment following the cementation, causes fragmentation and surface fraction reduction of the tantalum carbides which strengthen the alloy.
\end{abstract}

Keywords: Pack-cementation, chromium, cobalt alloy, tantalum carbide, high temperature oxidation.

\section{INTRODUCTION}

Metallic pieces used at high temperature in gaseous aggressive environments are more or less rapidly deteriorated by high temperature oxidation and/or hot corrosion, with detrimental consequences for their lifetime [1]. In order to delay the start of catastrophic oxidation, refractory alloys must contain sufficient amounts of $\mathrm{Cr}, \mathrm{Al}$ or $\mathrm{Si}$, at least in their subsurface. This is notably true for cobalt-based [2] and nickelbased [3] superalloys, and also for molybdenum or niobiumbased [4] refractory alloys. In some applications it is specifically a high chromium content which is required, for example for allowing hot pieces to resist corrosion by molten glass or molten salts, in addition to oxidizing gases. It is then generally considered that the required minimal chromium contents are about $20 \mathrm{wt} . \% \mathrm{Cr}$ in a nickel-based alloy, and $30 \mathrm{wt} . \%$ in a cobalt-based alloy. Unfortunately, in another way such high chromium contents risk to be detrimental for mechanical properties since they can lower the fusion start temperature of the alloy or promote metallurgical instabilities (brittle phases' precipitation). The presence of such high chromium contents are not necessary in the whole alloy since only external surface and sub-surface are affected by oxidation at high temperature. An inhomogeneous distribution of chromium (high near the surface and low in the bulk) may permit simultaneously keeping a good resistance to high temperature oxidation on surface, and preventing any precipitation in the bulk of brittle sigma phases which are usually favored by high chromium concentrations. Obtaining such chromium repartition is possible by enriching in

*Address correspondence to this author at the Institut Jean Lamour (UMR CNRS 7198), Department 2 - Chemistry and Physics of Solids and Surfaces, Nancy - University, B.P. 70239, 54506 Vandoeuvre-lès-Nancy, France; Tel: (+33) 3836846 66; Fax: (+33) 3836846 11;

E-mail: patrice.berthod@ijl.nancy-universite.fr chromium the sub-surface of a low-chromium alloy, using pack-cementation.

Pack-cementation is a well-known CVD method which allows depositing one or more elements on the surface of an alloy. It has been employed since the 60 's or before, to superficially enrich metallic substrates with various elements, e.g. aluminum on Nb-based alloys [5], Ni-based alloys [6,7] or Co-based alloys [8], silicon on steels [9] and Ni-based alloys [10], boron on Fe- [11] and Ti-based [12] alloys, manganese on steels [13]. Today there is still a research dynamism on the subject, as demonstrated by the following articles taken out of the most recent ones: aluminum-deposits on steels [14], Ni-based alloys [15] and Mo-Si-B alloys [16], silicon on Nb-based alloys [17,18] and on Mo- and/or W-based alloys [19]. The principal purpose of pack-cementation deposits is protection of alloys against hot oxidation or corrosion, but this technique can also be met when alloys need to be protected for uses at ambient temperatures [20].

In contrast, although the chromium enrichment of cobaltbased alloys by pack-cementation was subjected to some works in the past [21] it appears that there are very few published studies about that. The aim of the present work is precisely to test the deposition of chromium using packcementation to protect very refractory and mechanically resistant (but low-chromium) cobalt-based alloys reinforced by tantalum carbides, and evaluate the behavior in high temperature oxidation of such alloys when coated by $\mathrm{Cr}$ pack cementation.

\section{MATERIALS AND METHODOLOGY}

\section{Synthesis of the Alloys and Metallographic Preparation}

The cobalt-based alloys initially elaborated by foundry are two alloys Co-10Cr-xC-yTa (with $\mathrm{x}=0.25$ and $0.50 \mathrm{wt} . \%$, 
and $\mathrm{y}=4.4$ and 8.7 wt.\% respectively). They are called "CoTa1" and "CoTa2". They were synthesized by high frequency induction melting (CELES furnace, $300 \mathrm{kHz}$ max.) under inert atmosphere (300mbars of Argon). The initial charges were composed of pure elements: $\mathrm{Co}, \mathrm{Cr}, \mathrm{C}$ (graphite) and Ta. Each charge, of about $40 \mathrm{~g}$, underwent a first fusion. Thereafter the liquid alloy was solidified in the water-cooled copper crucible of the high frequency induction furnace. The ingots were then melted again, and the liquid alloys were poured in a cylindrical copper mould in which they solidified with the form of a cylindrical ingot (length $50 \mathrm{~mm}$, diameter $10 \mathrm{~mm}$ ). For each alloy, the latter was cut for obtaining several disks (diameter $10 \mathrm{~mm}$, thickness $2.5 \mathrm{~mm}$ ). One disk per alloy was mounted in resin and polished with $\mathrm{SiC}$ papers from 240 -grit to 1200 -grit. The final polishing was done using a textile paper enriched in $1 \mu \mathrm{m}$ diamond particles. These metallography samples were thereafter used to examine the microstructures of the alloys before cementation, using a Scanning Electron Microscope (SEM, type: Philips XL30), generally in Back Scattered Electrons (BSE) mode and under an acceleration voltage of $20 \mathrm{kV}$.

\section{Pack-Cementation Runs}

The other disks were prepared to be coated by cementation. Some of the latter were additionally heattreated to ensure the inwards diffusion of the deposited chromium. Before cementation the disks were polished up to 1200 -grit paper and placed in a silica flask containing the cement. The latter consisted in a mixture of: (1) powder of pure $\mathrm{Cr}$ (playing the role of master alloy), (2) powder of $\mathrm{CrCl}_{3}$ (the halide activator), and (3) powder of $\mathrm{Al}_{2} \mathrm{O}_{3}$ (the inert filler material). A secondary vacuum was achieved in the silica flask containing the alloy disks and the mixed powders. The flask was closed under vacuum and placed in a furnace in which it was exposed at $1050^{\circ} \mathrm{C}$ for $15 \mathrm{~h}$. After cooling down to room temperature, the grains of cement or of alumina still stuck to the disks' surfaces were removed by washing with ethanol and by performing ultrasonic cleaning. Per alloy one $15 \mathrm{~h}$-cemented disk was destined to metallographic characterization and another $15 \mathrm{~h}$-cemented disk was heat-treated at $1200^{\circ} \mathrm{C}$ for $75 \mathrm{~h}$ under vacuum, for allowing chromium diffusing deeper in the alloy.

\section{Oxidation Tests}

A $\{15 \mathrm{~h}$-cemented; 75h-heat-treated $\}$ sample (more briefly called "C15HT75") of each alloy were slightly polished with 1200-grit $\mathrm{SiC}$ paper. They underwent oxidation at $1200^{\circ} \mathrm{C}$, during which their mass variations were measured and recorded, for 50 hours in a Setaram TGA92 thermobalance in an air flow of $1.5 \mathrm{~L} / \mathrm{h}$ of dry $80 \% \mathrm{~N}_{2}-20 \% \mathrm{O}_{2}$. The analysis of the mass gain versus time data was performed in order to determine both the parabolic rate constant $K_{p}$ and the volatilization constant $K_{v}$, for a better characterization of the oxidation rate. Indeed, at $1200^{\circ} \mathrm{C}$ a part of the external chromia $\left(\mathrm{Cr}_{2}{ }_{2} \mathrm{O}_{3}\right)$ scale may be more or less rapidly re-oxidized in a new oxide $\left(\mathrm{Cr}^{\mathrm{VI}} \mathrm{O}_{3}\right)$, gaseous at these temperatures. Taking into account this phenomenon may avoid any minimization of the parabolic oxidation kinetic. The mass gain files were numerically treated according to the equation [22]: $m \cdot \frac{d m}{d t}=K_{p}-K_{v} . m$, in which $\mathrm{m}$ is the mass gain per surface unit area. The variation of $m \cdot \frac{d m}{d t}$ versus $-m$ may lead to a straight line, for which the ordinate at the origin is equal to $\mathrm{K}_{\mathrm{p}}$ and the slope is equal to $\mathrm{K}_{\mathrm{v}}$.

\section{Metallographic Characterization}

The enrichments in chromium on surface and in the subsurface, just after cementation and after the diffusion heattreatment, as well as the chromium impoverishments after oxidation test, were characterized by concentration profiles measurements using EPMA/WDS (Electron Probe Micro Analysis/Wavelength Dispersion Spectrometry), with Cameca microprobes (models SX 50 and SX100). Two profiles per sample were performed, over several hundreds of micrometers in depth.

\section{RESULTS}

\section{Chemical Compositions of the Alloys and Microstructures Before Cr-Deposit}

The chemical compositions of the elaborated alloys, as analyzed using EPMA/WDS, are (in weight percents):

$$
\begin{aligned}
& \text { - Co (bal.) }-0.25 \mathrm{C}-10.3 \pm 0.1 \mathrm{Cr}-4.5 \pm 0.4 \mathrm{Ta} \text { for } \\
& \text { CoTa1 } \\
& \text { - } \quad \text { Co(bal.) }-0.50 \mathrm{C}-10.5 \pm 0.1 \mathrm{Cr}-8.5 \pm 1.5 \mathrm{Ta} \text { for } \mathrm{CoTa} 2
\end{aligned}
$$

Their initial microstructures are illustrated by the micrographs presented in Fig. (1). The two alloys are composed of a dendritic matrix and tantalum carbides forming an eutectic with matrix in the interdendritic spaces. The tantalum carbides network is significantly more developed in the CoTa2 alloy than in the CoTa1 one.

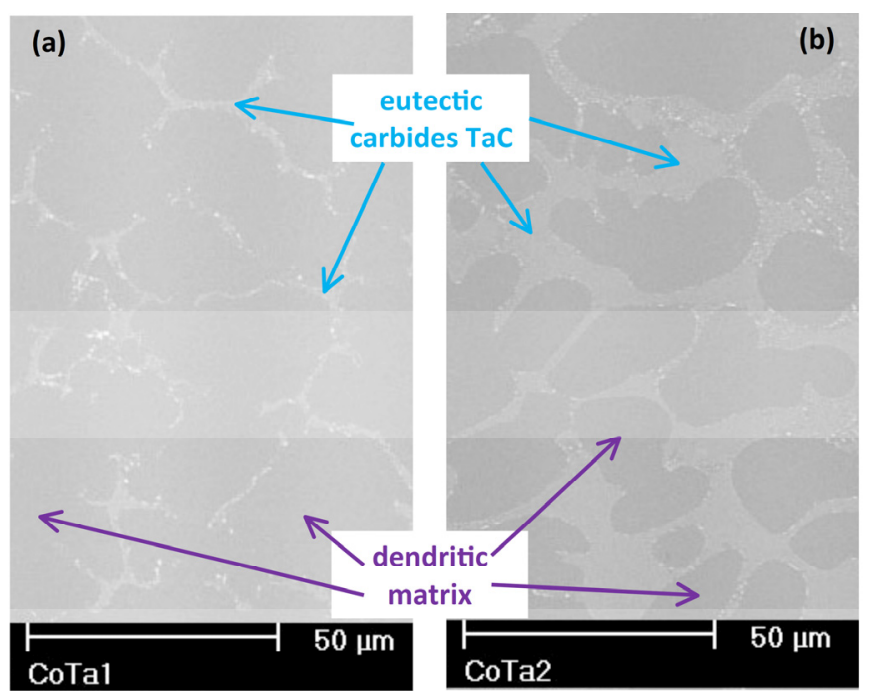

Fig. (1). As-cast microstructures of the studied cobalt-based alloys: (a) CoTa1 and (b) CoTa2 (SEM micrographs in BSE mode).

\section{Chromium Enrichment After Cementation and Heat- Treatment}

The cementation of the two alloys led to the incorporation of chromium in their metallic sub-surface, 
without formation of any carbide layer as sometimes encountered for other carbides-containing alloys (e.g. when most of the interdendritic carbides are chromium carbides). This resulted in a mass gain of about $32 \mathrm{mg} / \mathrm{cm}^{2}$ for CoTa1 and $24 \mathrm{mg} / \mathrm{cm}^{2}$ for CoTa2. Some grains of chromium cement were still stuck to the surface of the alloys (Fig. (2a) for CoTa1 and Fig. (3a) for CoTa2) despite washing. From several tens of micrometers under the cement/alloy interface (as illustrated in Fig. (4a) in the case of CoTa1), the chromium content starts increasing from the $10 \mathrm{wt} \% \mathrm{Cr}$ value in the bulk and reaches around $35 \mathrm{wt} . \%$ for the two alloys on the extreme surface $(33 \pm 2 \mathrm{wt} . \% \mathrm{Cr}$ for CoTal and $34.5 \pm 3$ wt. $\% \mathrm{Cr}$ for CoTa2).

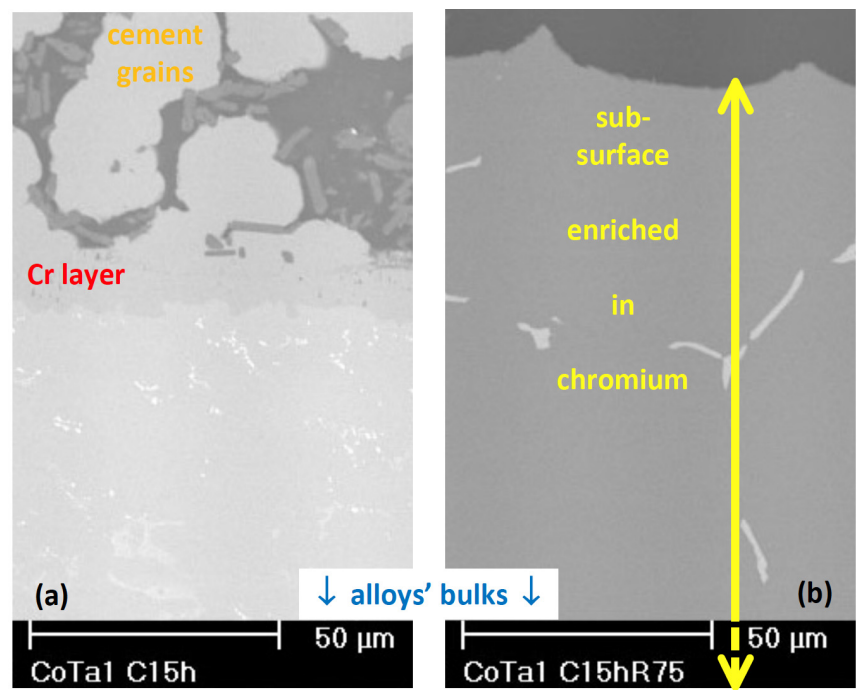

Fig. (2). Surface states of the CoTa1 alloy (a) after cementation and (b) after diffusion heat-treatment (SEM micrographs in BSE mode).

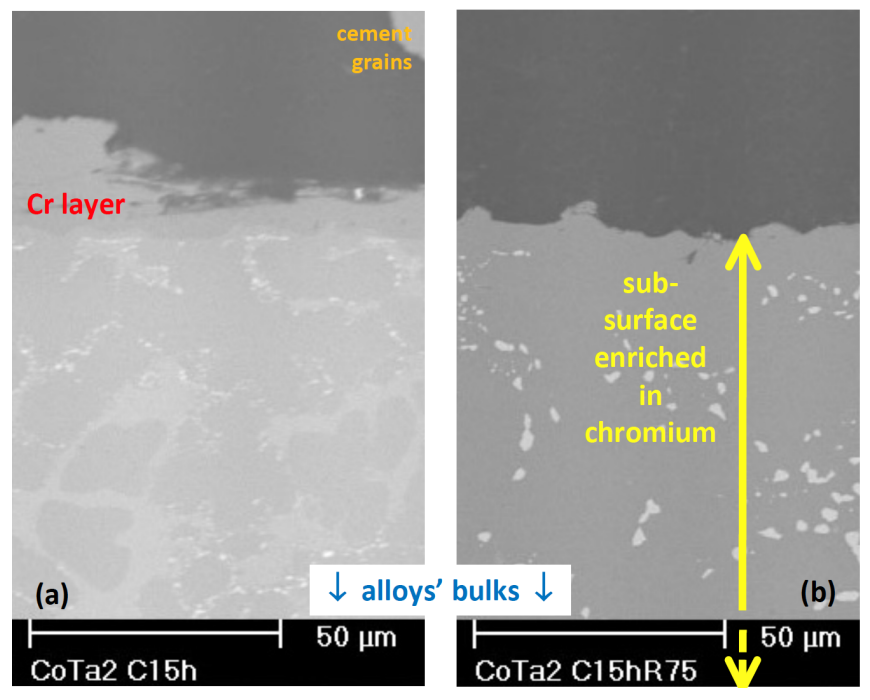

Fig. (3). Surface states of the CoTa2 alloy (a) after cementation and (b) after diffusion heat-treatment (SEM micrographs in BSE mode).

After cementation, the 75h-long heat treatment (Fig. (2b) for CoTa1 and Fig. (3b) for CoTa2) induced a deeper diffusion of chromium in the alloy, also accompanied by the disappearance of the $\mathrm{Cr}$ cement grains initially stuck on surface. This resulted in a small decrease in maximal $\mathrm{Cr}$ content of the external surface $(29.5 \pm 0.5 \mathrm{wt} . \% \mathrm{Cr}$ for the two alloys). Due to this heat-treatment the external zone of alloy enriched in chromium has become significantly more extended since it was then about $195 \mu \mathrm{m}$ for CoTa1 (Fig. 4b) and $230 \mu \mathrm{m}$ for CoTa2 (Fig. 4c).

\section{Thermogravimetry Runs}

Two thermogravimetry tests were performed at $1200^{\circ} \mathrm{C}$ for 50 hours with the samples of CoTa1 and CoTa2 alloys, previously cemented and heat-treated. The obtained mass gain curves are given in Fig. (5a) for CoTal (thick purple dots) and in Fig. (6a) for CoTa2 (thick blue dots). After a short initial linear part the mass gain became parabolic. This behaviour was lost after a little more than 10 hours by the CoTa1 alloy, while the oxidation kinetic remained parabolic until the end for CoTa2. The values of the two kinetic constants, the parabolic $\mathrm{Kp}$ and the rate of chromia volatilization $\mathrm{Kv}$, were extracted from the mass gain measurements by applying the $\left\{\mathrm{dm} \times \mathrm{dm} / \mathrm{dt}=\mathrm{K}_{\mathrm{p}}-\mathrm{K}_{\mathrm{v}} \times \mathrm{m}\right\}$ treatment (Fig. (5b) for CoTa1 and Fig. (6b) for CoTa2). This led to $\mathrm{K}_{\mathrm{p}}=78.3 \times 10^{-12} \mathrm{~g}^{2} \mathrm{~cm}^{-4} \mathrm{~s}^{-1}$ and $\mathrm{K}_{\mathrm{v}}=212 \times 10^{-10}$ $\mathrm{g} \mathrm{cm}^{-2} \mathrm{~s}^{-1}$ for the CoTa1 alloy (parabolic part of the curve) and $\mathrm{K}_{\mathrm{p}}=66.0 \times 10^{-12} \mathrm{~g}^{2} \mathrm{~cm}^{-4} \mathrm{~s}^{-1}$ and $\mathrm{K}_{\mathrm{v}}=118 \times 10^{-10} \mathrm{~g} \mathrm{~cm}^{-2}$ $\mathrm{s}^{-1}$ for the CoTa2 alloy (for the whole curve). These values of parabolic constants and volatilization constants were validated by the good correspondence, with the experimental mass gain curves, of the synthetic curves plotted using the values of $K_{p}$ and $K_{v}$ previously determined: small pink dots in Fig. (5a) for the CoTa1 alloy and small red dots in Fig. (6a) for the CoTa2 alloy. The $\mathrm{K}_{\mathrm{v}}$ values are also in good agreement with other ones obtained earlier on other chromiaforming tantalum-containing nickel-based and cobalt-based alloys $[23,24]$ or directly on sintered $\mathrm{Cr}_{2} \mathrm{O}_{3}[25,26]$. Their determination avoided minimizing the parabolic constants, the values of which are also at the same level as what is usually measured for chromia-forming cobalt-based superalloys [24].

\section{Surfaces States of the Oxidized Alloys}

After oxidation test, the CoTa1 (Fig. 7a), and CoTa2 (Fig. 8a, b) are covered by a continuous $\mathrm{Cr}_{2} \mathrm{O}_{3}$ scale (thickness of several tens of $\mu \mathrm{m}$ ). Just under the chromia layer the most external part of the sub-surface is affected by internal oxidation, with the appearance of an irregular pale oxide of both chromium and tantalum $\left(\mathrm{CrTaO}_{4}\right)$, the thickness of which varies along the oxidation front. Such products of oxidation are classical since they are usually encountered for tantalum-containing cobalt-based alloys. In some locations on the surface of an oxidized sample, oxidation penetration is several $\mu \mathrm{m}$ deeper than elsewhere all around the cross-section in the case of the CoTal alloy (Fig. 7b): oxidation became here catastrophic which induced the accelerated mass gain seen on the corresponding thermogravimetry curve (Fig. 5a).

\section{New Chromium Distribution in the Alloys After Oxidation}

Oxidation for $50 \mathrm{~h}$ at $1200^{\circ} \mathrm{C}$ has logically impoverished the sub-surface in chromium and the alloys have lost a significant part of the supplementary chromium previously added. The two oxidized samples are characterized by chromium profiles presenting a bulge about $80-100 \mu \mathrm{m}$ under the external surface. This is clearly visible on the WDS- 


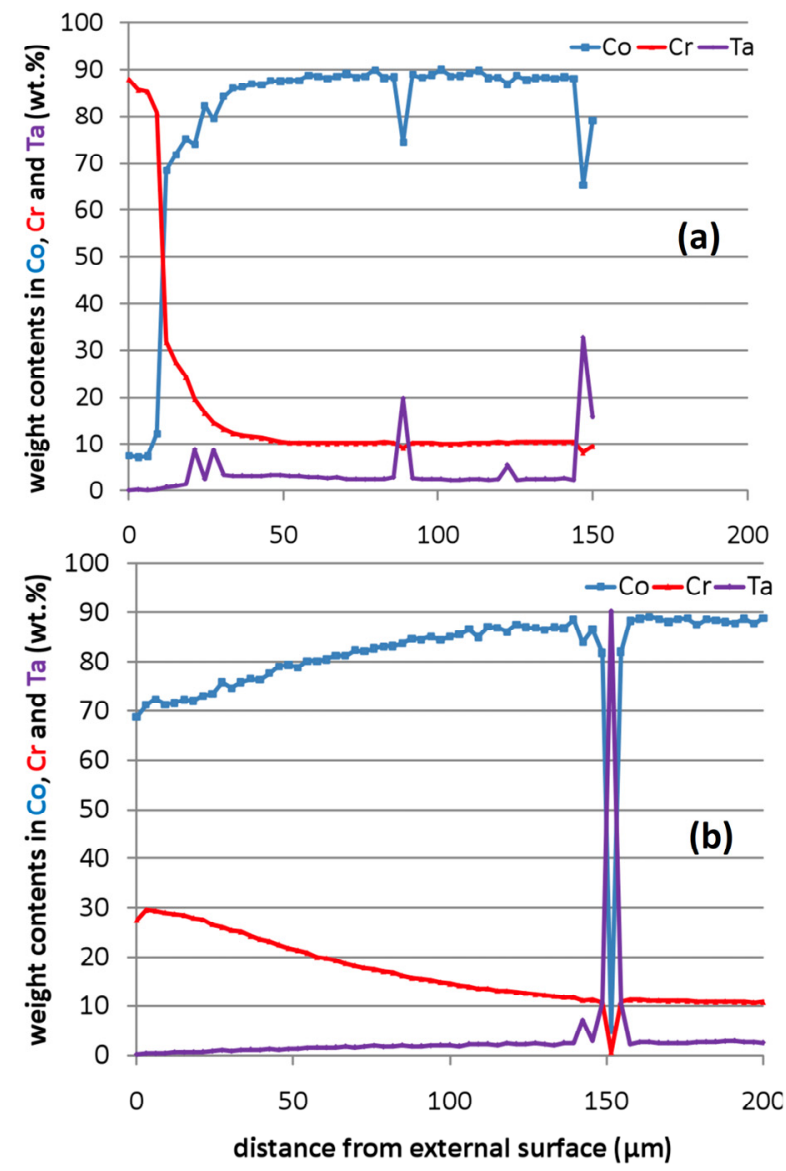

\section{$\leftarrow$ CoTa1 only cemented}

CoTa1 cemented and heat-treated $\leftarrow$
CoTa2 cemented and heat-treated

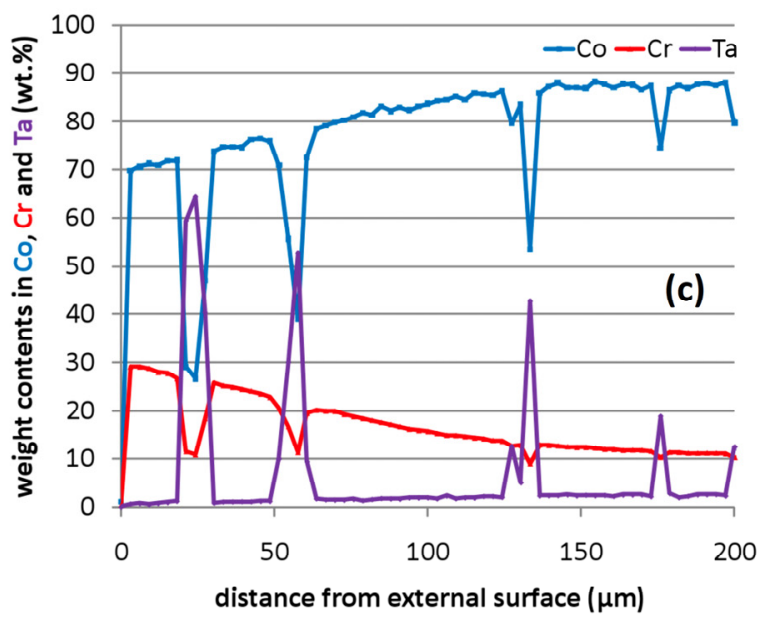

Fig. (4). EPMA/WDS concentrations profiles perpendicular to the external surface, for (a) CoTal after cementation, (b) CoTal after cementation and heat-treatment, (c) for $\mathrm{CoTa} 2$ after cementation and heat-treatment.

(a)
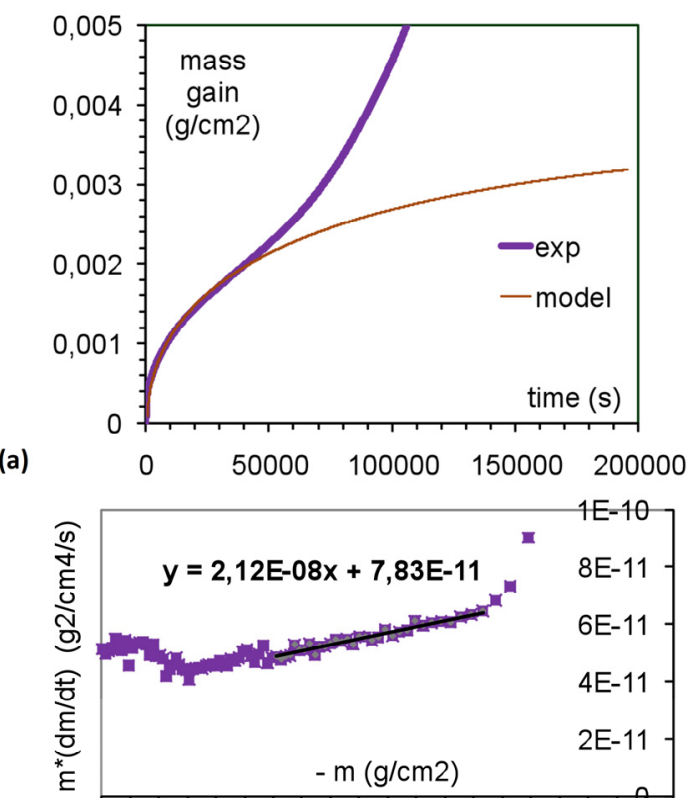

(b)

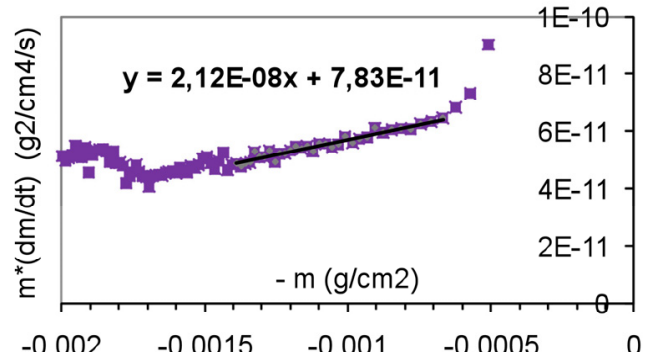

Fig. (5). Thermogravimetry results obtained at $1200^{\circ} \mathrm{C}$ for the cemented +heat-treated CoTa1, (a) experimental mass gain curve and synthetic curve plotted using the $\mathrm{K}_{\mathrm{p}}=78 \times 10^{-12} \mathrm{~g}^{2} \mathrm{~cm}^{-4} \mathrm{~s}^{-1}$ and $\mathrm{K}_{\mathrm{v}}=212 \times 10^{-10} \mathrm{~g} \mathrm{~cm}^{-2} \mathrm{~s}^{-1}$ values determined in (b) using the $m \times \frac{d m}{d t}=K_{p}-K_{v} \times m$ plot.

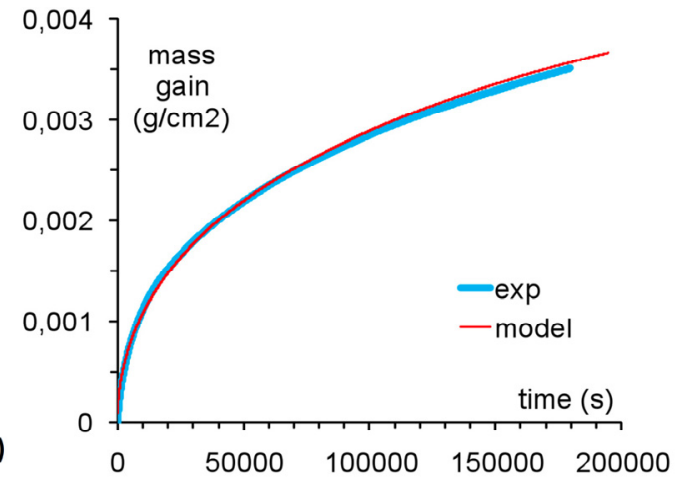

(a)

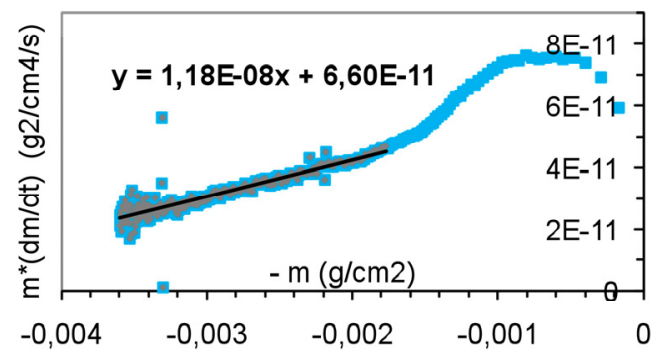

Fig. (6). Thermogravimetry results obtained at $1200^{\circ} \mathrm{C}$ for the cemented +heat-treated CoTa2, (a) experimental mass gain curve and synthetic curve plotted using the $\mathrm{K}_{\mathrm{p}}=66 \times 10^{-12} \mathrm{~g}^{2} \mathrm{~cm}^{-4} \mathrm{~s}^{-1}$ and $\mathrm{K}_{\mathrm{v}}=118 \times 10^{-10} \mathrm{~g} \mathrm{~cm}^{-2} \mathrm{~s}^{-1}$ values determined in (b) using the $m \times \frac{d m}{d t}=K_{p}-K_{v} \times m$ plot. 
EPMA chromium concentration profiles, superimposed with the initial profiles, in Fig. (9a) for the CoTal alloy and in Fig. (9b) for the CoTa2 alloy. From the oxidation front, the chromium content increases from a low value (about $8 \mathrm{wt} . \%$ for CoTa1 and $11 \mathrm{wt} . \% \mathrm{Cr}$ for $\mathrm{CoTa} 2$ ), reaches a maximal value (about $14 \mathrm{wt} . \%$ in both cases) at depths equal to about $80 \mu \mathrm{m}$ for CoTa1 and $95 \mu \mathrm{m}$ for CoTa2. The chromium content thereafter decreases slowly and finishes to join the initial chromium content of the alloy before cementation (about 10wt.\%), at depths of about 225 and $240 \mu \mathrm{m}$ for CoTa1 and CoTa2 respectively, that is to say a little deeper than before oxidation (about $195 \mu \mathrm{m}$ for CoTal and $230 \mu \mathrm{m}$ for CoTa2 after cementation and heat-treatment). The maximal chromium bulge was thus progressively shifted inwards.
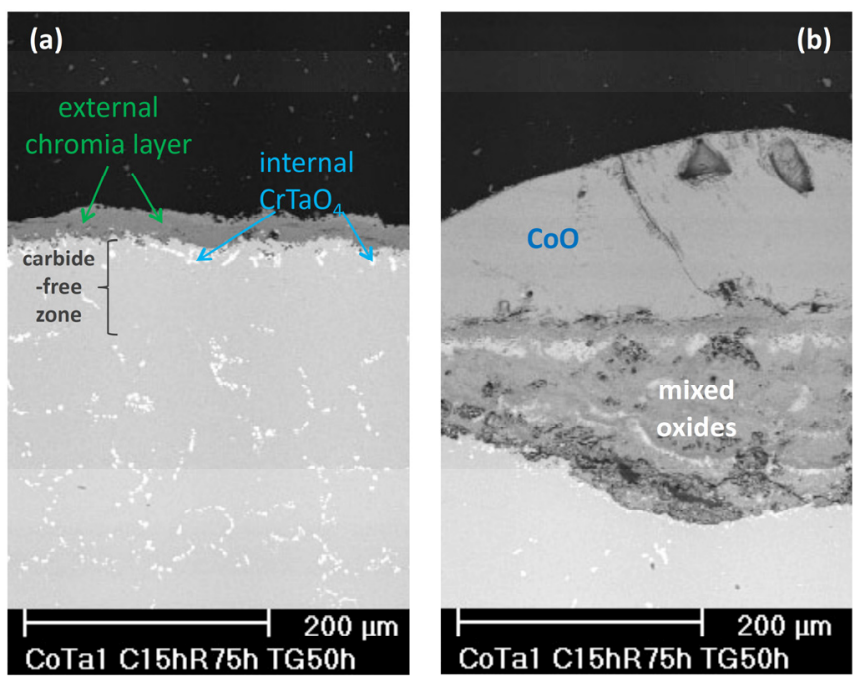

Fig. (7). Surface states of the CoTa1 alloy after thermogravimetric oxidation for $50 \mathrm{~h}$ at $1200^{\circ} \mathrm{C}$, in a sample zone still chromia-forming (a) and in a zone where catastrophic oxidation (b) already started.

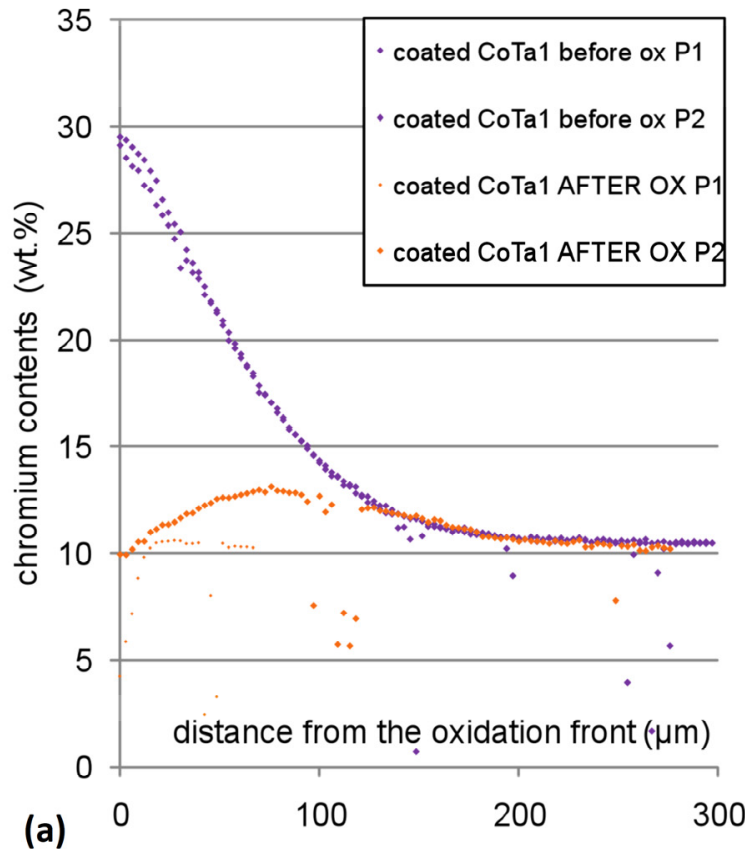

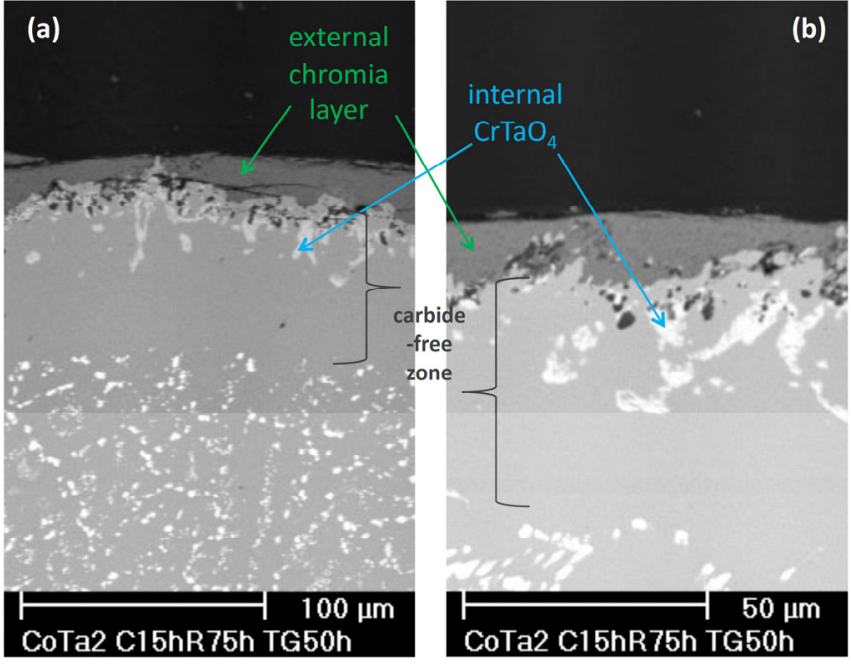

Fig. (8). Surface states of the CoTa2 alloy after thermogravimetric oxidation for $50 \mathrm{~h}$ at $1200^{\circ} \mathrm{C}$ (all the surface was still covered by a protective chromia scale).

\section{DISCUSSION}

The pack-cementation runs performed for the two cobaltbased alloys of this study resulted in a significant subsurface enrichment in chromium in both cases, with a chromium content reaching $30 \mathrm{wt} . \%$ on surface after diffusion heat-treatment. The inward diffusion of chromium was a little faster in the case of the CoTa2 alloy by comparison with CoTa1. This can result from the preferential diffusion along the interfaces separating the dendritic matrix and the carbide network. Inwards chromium diffusion is more helped by the carbides network of the CoTa2 alloy than by the one of CoTa1 which was less developed than the former because of its lower carbon and tantalum contents.

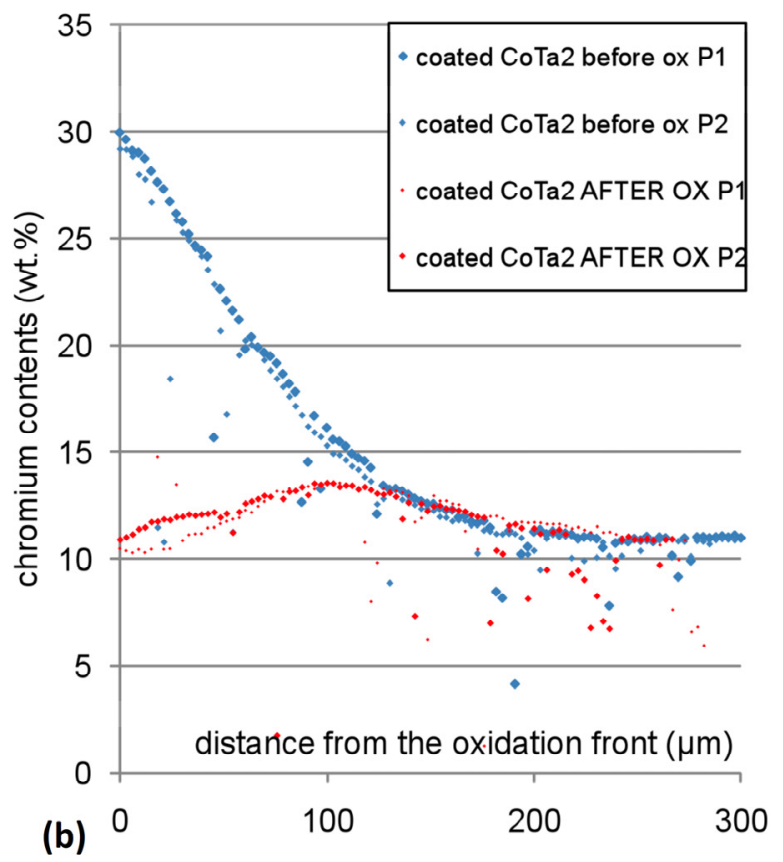

Fig. (9). Chromium concentration profiles of the cemented + heat-treated (a) CoTa1 and (b) CoTa2 alloys before and after 50h of oxidation at $1200^{\circ} \mathrm{C}$. 
These additional chromium quantities, brought by cementation and spread deeper by the diffusion heattreatment, represent useful reserves in chromium to combat high temperature oxidation with efficiency although the chromium content in the bulk (10wt.\% here) is at a level low enough for allowing catastrophic oxidation in absence of any protective coating. The presence of the chromium reservoir in the first hundreds of micrometers from the external surface allowed the two alloys resisting for 50 hours against oxidation in air at $1200^{\circ} \mathrm{C}$ (which is a service temperature very high for cobalt-based alloys).

As for other TaC-containing cast alloys, and for the same reasons as given before about the initial inward $\mathrm{Cr}$ diffusion during cementation and heat-treatment, the carbides present in the interdendritic spaces of the CoTa1 and CoTa2 alloys facilitated the outward diffusion of chromium during oxidation. They promoted thus an efficient supply of this element on the oxidation front to constitute then maintain the chromia protective scale. The $\mathrm{Cr}$ diffusion-helping role of tantalum carbides was, here too, better for the TaC-richest CoTa2 alloy, as shown by the slightly higher $\mathrm{Cr}$ content on the alloy surface (just under the chromia scale) by comparison with the CoTa1 one. This can be also at the origin of the lower $K_{p}$ and $K_{v}$ values observed for CoTa2 by comparison with CoTa1. These differences of $\mathrm{K}_{\mathrm{p}}$ and $\mathrm{K}_{\mathrm{v}}$ reveal the overall better quality of the chromia scale formed around the CoTa2 sample, by comparison with CoTa1. To summarize one can say that tantalum carbides favored both a rapid storage of chromium in the sub-surface (long cementation and diffusion heat-treatment are thus not really necessary) and, after, a fast releasing of this chromium for supplying the oxidation front with efficiency. Finally the CoTa2 alloy, which contained initially $10 \mathrm{wt} . \% \mathrm{Cr}$ but was $\mathrm{Cr}$-cemented and heat-treated, appears as oxidation resistant as the well-resistant simple $\mathrm{Ni}-30 \mathrm{Cr}$ as illustrated in Fig. (10) by their two mass gain curves obtained in the same conditions, and moreover infinitely better than a $\mathrm{Co}-30 \mathrm{Cr}$ binary alloy, despite of the high bulk's chromium content of the latter: another illustration of the TaC-network utility.

However, the cementation run, and especially the too long diffusion heat-treatment (performed at a too high temperature), induced fragmentation and coarsening of the tantalum carbides of both alloys, as illustrated in Fig. (11) for CoTa1 and in Fig. (12) for CoTa2, by SEM micrographs taken before and after cementation + heat-treatment. Such $\mathrm{TaC}$ evolution, due to the convergence of the microstructures to new ones with minimized interfacial energies, may be unfortunately detrimental for the mechanical properties of the bulk.

\section{CONCLUSION}

Sub-surface chromium enrichment of cobalt-based alloys strengthened by tantalum carbides is possible using the packcementation technique. The outer part of the studied alloys were then sufficiently enriched in chromium to be able to resist a long time to oxidation at a temperature as high as $1200^{\circ} \mathrm{C}$. The $\mathrm{TaC}$ carbides reinforcing these alloys did not obstruct the Cr-enrichment process as it can occur in the case of other types of carbides less stable at high temperature. On the contrary they helped the Cr-incorporation by a faster diffusion along the matrix-carbides interfaces, a beneficial effect of the same nature that the easier diffusion for chromium to join the oxidation front when the alloy is in a situation of high temperature oxidation. However the cementation and diffusion heat-treatment parameters need to be optimized to obtain the same results, and maybe improve them again, with a more limited deterioration of the strengthening carbides network.
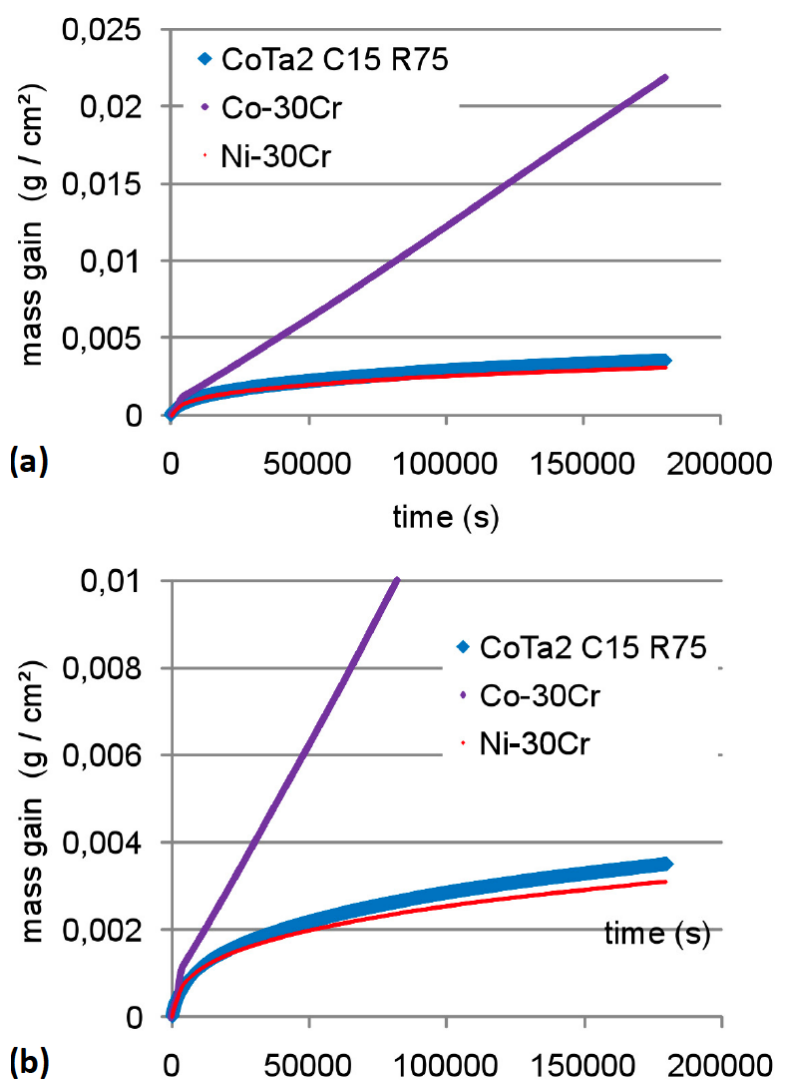

Fig. (10). Comparison of mass gain curves at $1200^{\circ} \mathrm{C}$ between the cemented+heat-treated CoTa2 alloy and the two binary alloys Co$30 \mathrm{wt} . \% \mathrm{Cr}$ and $\mathrm{Ni}-30 \mathrm{wt} . \% \mathrm{Cr}$ alloys; full scale (a) and enlarged (b).
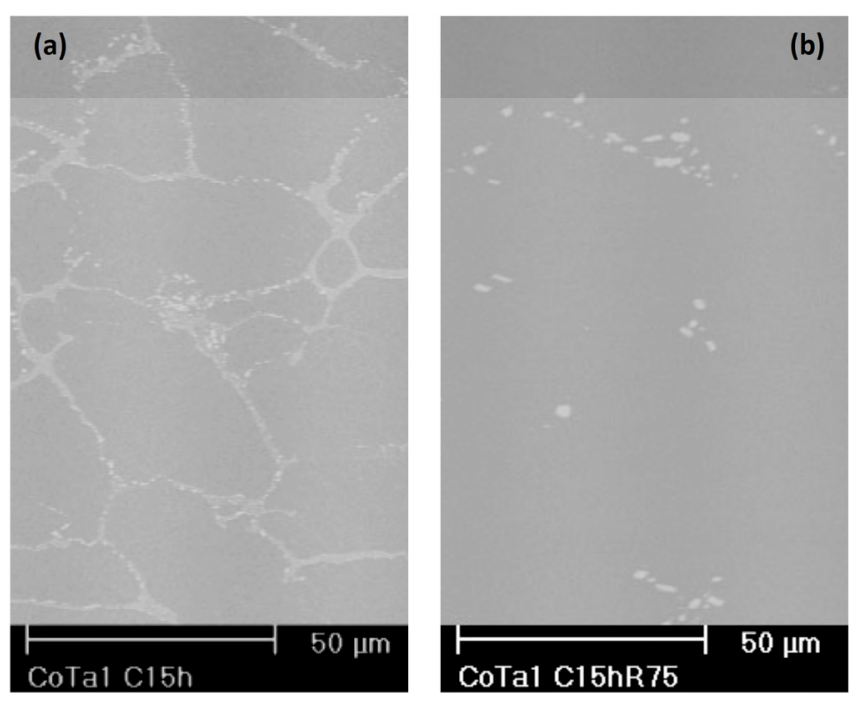

Fig. (11). Comparison of the CoTal microstructures after cementation only (a) and after cementation and heat-treatment (b); visualization of the $\left\{75 \mathrm{~h}, 1200^{\circ} \mathrm{C}\right\}$ heat-treatment effect on the tantalum-carbides morphology and coarseness. 

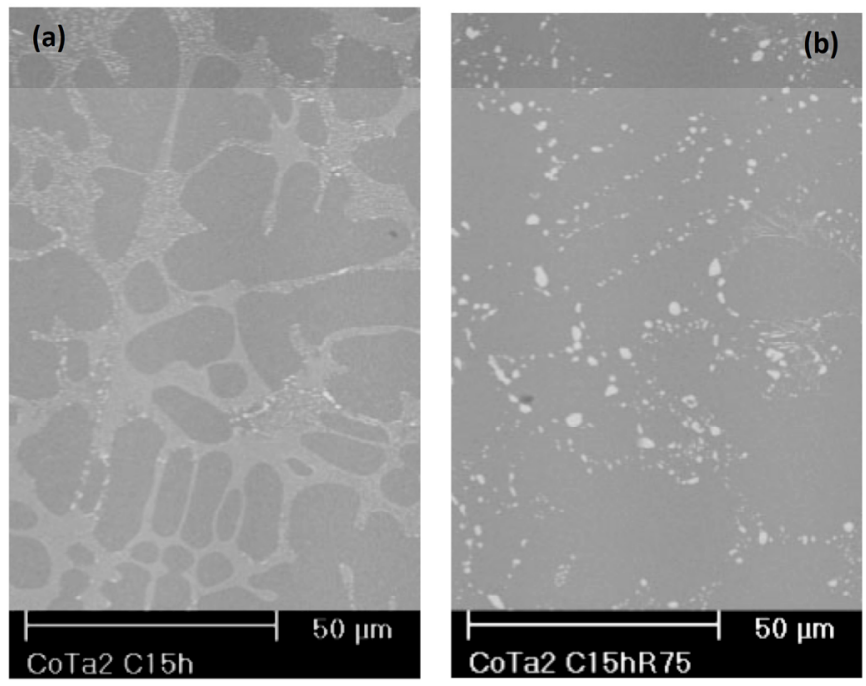

Fig. (12). Comparison of the $\mathrm{CoTa} 2$ microstructures after cementation only (a) and after cementation and heat-treatment (b); visualization of the $\left\{75 \mathrm{~h}, 1200^{\circ} \mathrm{C}\right\}$ heat-treatment effect on the tantalum-carbides morphology and coarseness.

\section{ACKNOWLEDGEMENTS}

The authors thank the Common Service of Microscopy and Microanalyses of the Faculty of Science and Techniques of the University Henri Poincaré Nancy 1, especially Sullivan De Sousa who performed the EPMA/WDS analyses.

\section{REFERENCES}

[1] Young DJ, High Temperature Oxidation and Corrosion of Metals. Elsevier: Amsterdam 2008.

[2] Beltram AM. Cobalt-base alloys. In: Sims CT, Stoloff NS, Hagel WC, Eds. Superalloy II - High Temperature Materials for Aerospace and Industrial Power. John Wiley-Interscience: New York 198; pp. 135-63.

[3] Pint BA, Tortorelli PF, Wright IG. Effect of cycle frequency on high-temperature oxidation behavior of alumina-forming alloys. Oxid Met 2002; 58(1/2): 73-101.

[4] Zamoum F, Benlaharche T, David N, Podor R, Vilasi M. Kinetics of high temperature oxidation of $(\mathrm{Nb}, \mathrm{Co}, \mathrm{Cr})_{7} \mathrm{Si}_{6}$ and $(\mathrm{Nb}, \mathrm{Co}, \mathrm{Cr})_{8} \mathrm{Si}_{7}$ silicide compounds. Intermetallics 2008; 16(4): 498-507.

[5] Slama G, Vignes A. Coating of niobium and niobium alloys with aluminium. Part II. Hot-dipped coatings. J Less Common Metals 1971; 23(4): 375-93

[6] Fleetwood MJ. Influence of nickel-base alloy composition on the behavior of protective aluminide coatings. J Inst Metals 1970; 98:17.

[7] Levine SR, Caves RM. Thermodynamics and kinetics of pack aluminide coating formation on IN-100. J Electrochem Soc 1974; 121(8): 1051-1064.
[8] Jackson MR, Rairden JR. Microstructure and chemistry of aluminide coating of $\mathrm{Ni}-\mathrm{Cr}$ and $\mathrm{Ni}-\mathrm{Co}-\mathrm{Cr}$ alloys. J Vacuum Sci Tech 1980; 17(1): 77-80.

[9] Mukherji AN, Prabhakaram P. Diffusion coatings on steel. AntiCorrosion Meth Mat 1978; 25(1): 4-8.

[10] Schneider K, Bauer R, Grünling HW. Corrosion and failure mechanisms of coatings for gas turbine applications. Thin Solid Films 1978; 54(3): 353-357.

[11] Singhal SC. A hard diffusion boride coating for ferrous materials. Thin Solid Films 1977; 45(2): 321-9.

[12] Singhal SC. Erosion-resistant coating for titanium and its alloys. Thin Solid Films 1978; 53(3): 375-81.

[13] Kornmann M, Rexer J, Dancoisne P, Anderson E. Manganese diffusion coating of steels. Metals Technol 1977; 4(4): 218-22.

[14] Bateni RM, Shaw S, Wei P, Petric A. Deposition of Fe-Al intermetallic coatings on solid oxide fuel cell (SOFC) interconnects by pack cementation. Mater Manufact Process 2009; 24(6): 626-32.

[15] Choux C, Chevalier S, Cadoret Y. Elaboration of nickel aluminide diffusion coatings: Application to oxidation resistance. Mater Sci Forum 2008; 595-598: 41-9.

[16] Rioult F, Sekido N, Sakidja R, Perepezko J H. Aluminum pack cementation on Mo-Si-B alloys. J Electrochem Soc 2007; 154(11): C692-C701.

[17] Vilasi M, Steinmetz J, Gaillard-Allemand B, Berton B, Chéreau P. Protective coatings for niobium alloy. J Adv Mater-Covina 2000; 32(2): 53-7.

[18] Guo XP, Zhao LX, Guan P, Kusabiraki K. Oxidation behavior and pack siliconized oxidation-resistant coatings of an Nb-based ultrahigh temperature alloy. Mater Sci Forum 2007; 561-565: 3714.

[19] Majumdar S, Sharma IG, Suri AK. Development of oxidation resistant coatings on Mo-30W alloy. Int Jof Refract Metals Hard Mat 2008; 26(6): 549-54.

[20] Park JS, Kim JM, Kim HY, Kang CS, Choi SW. Surface protection of magnesium alloys via pack cementation coatings with aluminum powder and chlorides. Mater Sci Forum 2010; 638-642: 793-798.

[21] Faber GH. Role of chromium in corrosion and oxidation resistant alloys and coatings. Proceeding of the conference High Temperature Alloys for Gas Turbines, Liege (Belgium) 25th -27 th September 1978

[22] Berthod P. Kinetics of high temperature oxidation and chromia volatilization for a binary $\mathrm{Ni}-\mathrm{Cr}$ alloy. Oxid Met 2005; 64(3/4): 235-252.

[23] Berthod P, Aranda L, Vébert C. Etude cinétique de l'oxydation à haute température et de la volatilisation de la chromine pour des superalliages de fonderie renforcés par carbures. Partie I: Cas d'alliages à base de nickel contenant du tantale. Ann Chim-Sci Mat 2006; 31(2): 213-235

[24] Berthod P, Raude S, Chiaravalle A. Etude cinétique de l'oxydation à haute température et de la volatilisation de la chromine pour des superalliages de fonderie renforcés par carbures. Partie II : Cas de superalliages à base de cobalt et influence de la finesse dendritique. Ann Chim-Sci Mat 2006; 31(2): 237-58.

[25] Hagel WC. Factors controlling the high-temperature oxidation of chromium. Transactions of the ASM 1963; 56: 583-99.

[26] Stearns CA, Kohl FJ, Fryburg GC. Oxidative vaporization kinetics of $\mathrm{Cr}_{2} \mathrm{O}_{3}$ in oxygen from 1000 to $1300^{\circ} \mathrm{C}$. J Electrochem Soc 1974 121(7): $945-51$.

(C) Michel et al.; Licensee Bentham Open.

This is an open access article licensed under the terms of the Creative Commons Attribution Non-Commercial License (http://creativecommons.org/licenses/by-nc/ 3.0/) which permits unrestricted, non-commercial use, distribution and reproduction in any medium, provided the work is properly cited. 